\title{
A Novel Process For Recovery Of Te And Se From Copper Slimes Autoclave Leach Solution
}

\author{
Shijie Wang, Brad Wesstrom and Jean Fernandez \\ Phelps Dodge Mining Company \\ El Paso Operations \\ 850 Hawkins Blvd., El Paso, TX 79915
}

\begin{abstract}
In pressure oxidation leaching of copper anode slimes, more than $65 \%$ of the tellurium is co-extracted during decopperizing. About $10-15 \%$ of the selenium is also dissolved simultaneously by severe leach conditions. Current operation for the treatment of the leachate is to constantly recirculate the leach solution through a bed of copper turnings. The tellurium and selenium are precipitated from the leach liquor as copper telluride and copper selenide and separated from the solution by filtration. In order to improve the reaction efficiency and reduce the process cost, viz. minimize the copper addition, cut retention time, and reduce the energy consumption; a chemical reducing agent is studied and the cementation process tested in the laboratory. In this paper, the test results are presented and the process chemistry is discussed.
\end{abstract}

Keywords : leaching, floatation, selenium, tellurium, copper.

\section{Introduction}

During the electrorefining of copper anodes, the insoluble components, anode slimes, settle to the bottom of the electrolytic cells. Anode slimes almost invariably contain copper, tellurium, selenium, silver, gold and traces of platinum group metals. In order to recover the precious metals from slimes, refineries must first complete the separation of copper, tellurium and selenium prior to refining silver and gold to pure products.

Phelps Dodge Refining Corporation - El Paso, (Figure 1), employs autoclaving for copper and tellurium removal in the slimes leach process. The autoclave, made of 904L stainless steel, is operated at a temperature of $150 \mathrm{~F}$, a line pressure of 80 psi oxygen and 1.5 to 4 hours of reaction time for a 5000 pound charge of slimes. The filtrate (leach solution) from the autoclave is then decanted and pumped into one of two cementation reactors (Figure 2). After the reactor is full, the solution is pumped to one of two copper chip towers, which are filled with copper chips. The cementation process is allowed to continue at $200^{\circ} \mathrm{F}$ for 24 hours while continuously circulating the filtrate. The copper telluride mud is then removed by filtration. The solution from the reactors/towers, if less than $30 \mathrm{ppm}$ tellurium, is pumped back to the tankhouse after clarification, as shown in Figure 3. Should the tellurium not be reduced below $30 \mathrm{ppm}$, the filtrate is discharged to the Water Treatment Plant for metal recovery. 


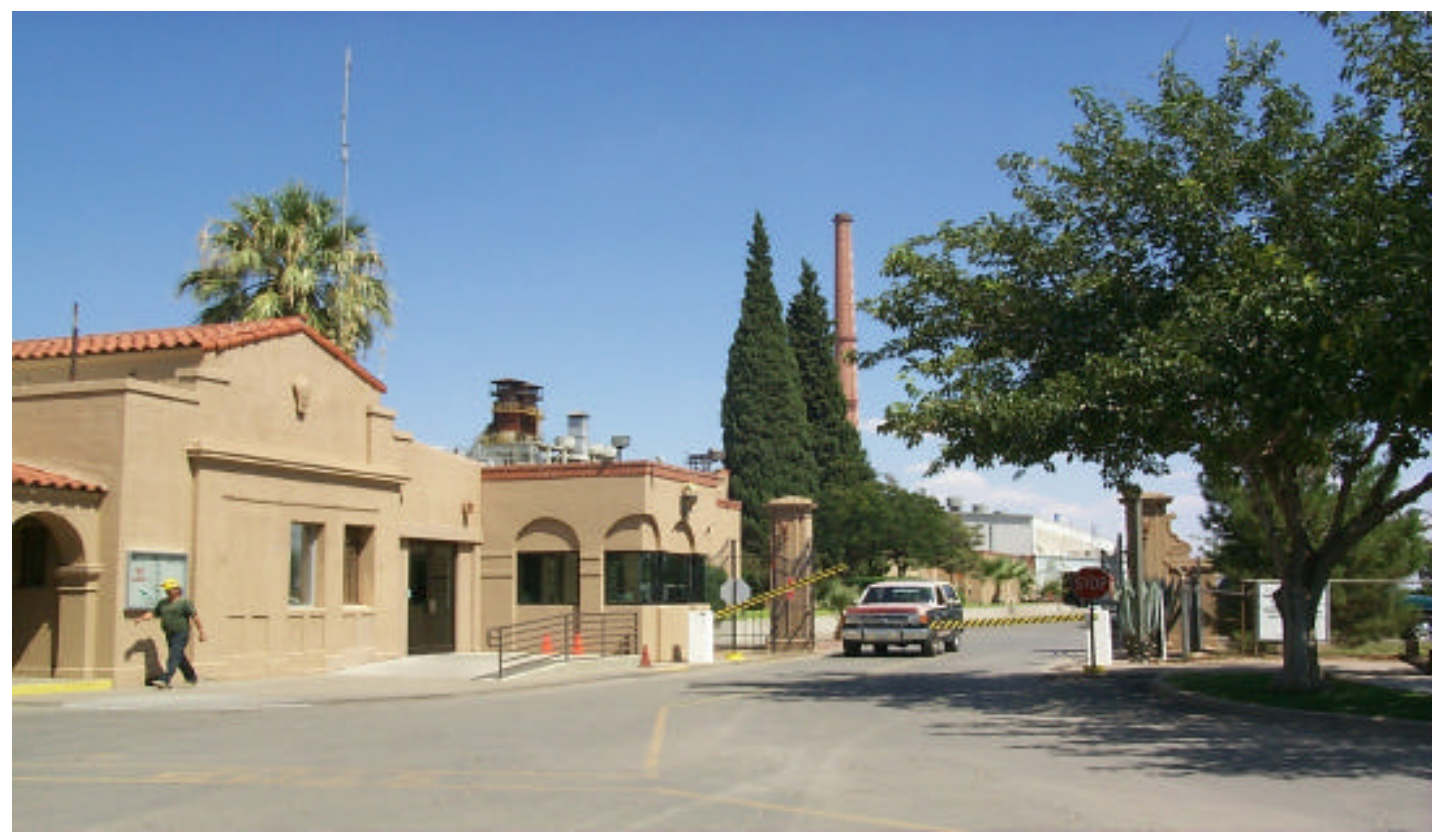

Figure 1. Phelps Dodge Refining Corporation - El Paso Works

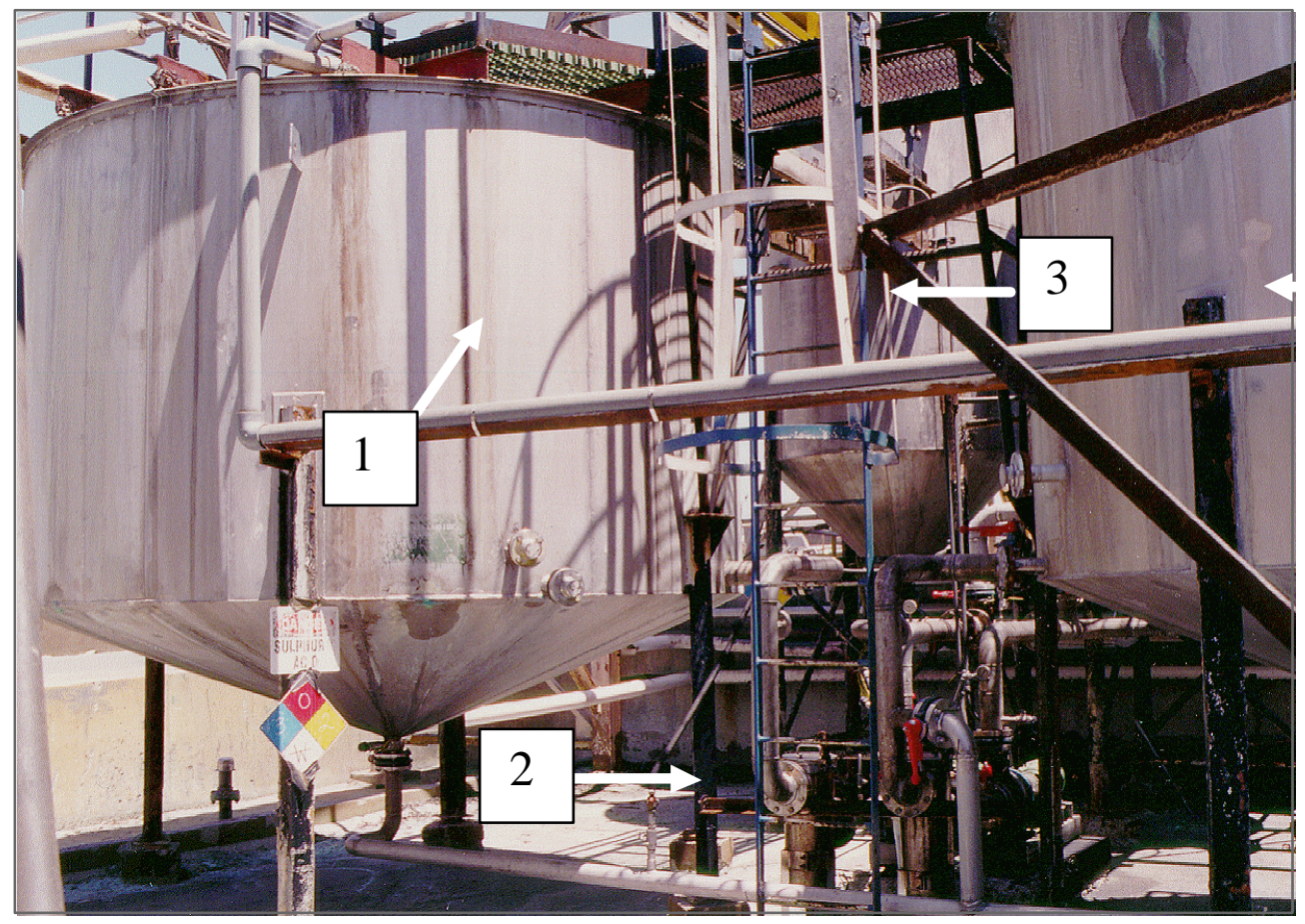

Figure 2. Cementation Reactors for Tellurium Recovery 1. Reactor; 2. Pump: 3. Copper Chip Tower 


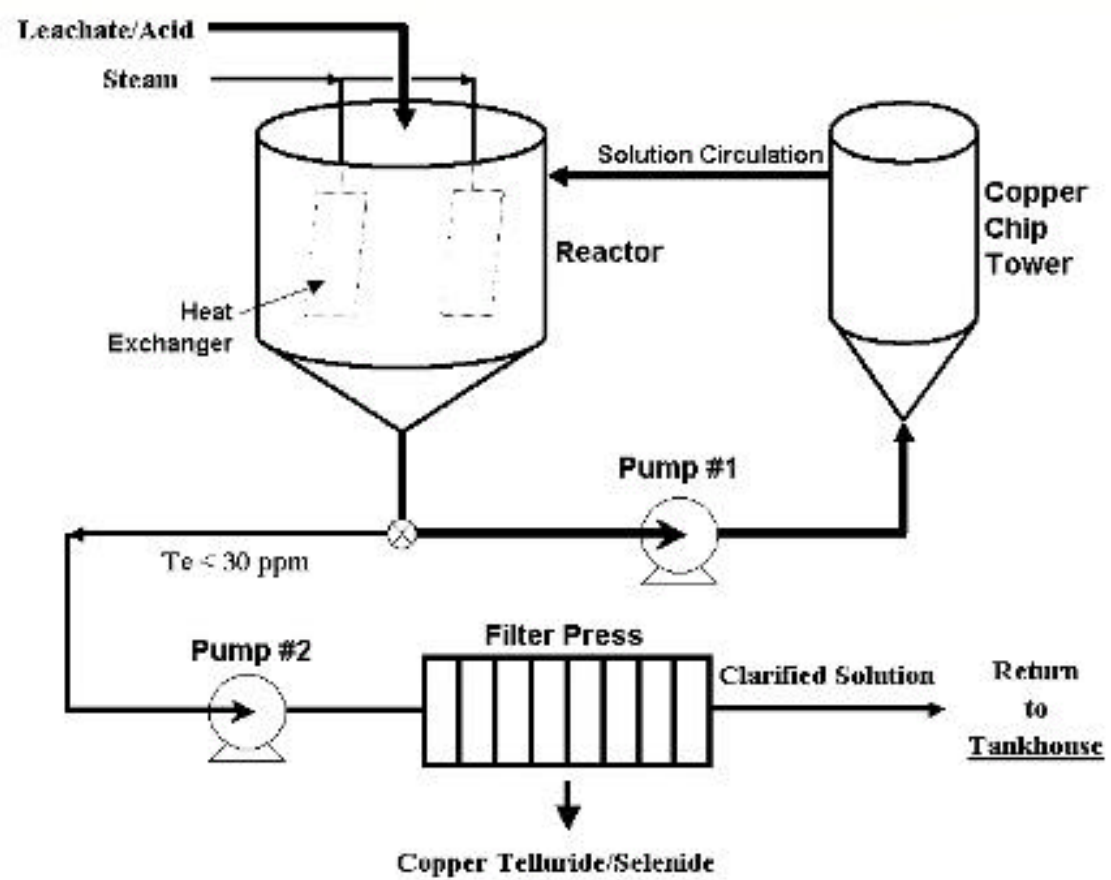

Figure 3.

After changes in anode feed from the smelter occurred, the anode slimes showed a refractory nature requiring severe leaching conditions in the autoclave for decopperizing. This resulted in some unwanted selenium being simultaneously co-extracted in the leach solution. Because of the higher concentrations of tellurium and selenium in the feed to the reactors/towers, the cementation process cost increased due to a significant amount of copper chips being consumed and extended cementing time needed.

A research project to improve the reaction efficiency and reduce the process cost was therefore undertaken to treat the high Te/Se content of the autoclave filtrate. In this paper, the process chemistry is discussed and the experimental results are presented.

\section{Chemistry of Process}

In order to investigate the reduction rates of selenium and tellurium from solution, sulfur dioxide is used as the reducing agent. Based on the phenomena observed and results obtained from the tests, the process chemistry is discussed.

First, sulfur dioxide reacts with tetravalent selenium in the solution containing $80 \mathrm{~g} / \mathrm{L}$ $\mathrm{H}_{2} \mathrm{SO}_{4}$. Electrochemical reduction of tetravalent selenium to elemental selenium can be expressed by the following equation:

$$
\mathrm{H}_{2} \mathrm{SeO}_{3(\mathrm{aq})}+2 \mathrm{SO}_{2(\mathrm{~g})}+\mathrm{H}_{2} \mathrm{O}_{(\mathrm{l})} \rightarrow 2 \mathrm{H}_{2} \mathrm{SO}_{4}(\mathrm{aq})+\mathrm{Se}_{(\mathrm{s})}(1)
$$


This reaction is likely dominant when the initial concentration of selenium is greater than $1 \mathrm{~g} / \mathrm{L}$ in solution.

The tellurium, however, can not be reduced significantly at this stage because the rate constant for tellurium varies as $\left[\mathrm{H}^{+}\right]^{-2}$, indicating much less possibility of reducing tellurium by sulfur dioxide in sulfuric acid media. ${ }^{1}$

Second, there is a disproportionation reaction with the formation of occasionally voluminous copper powder:

$$
2 \mathrm{Cu}^{+} \rightarrow \mathrm{Cu}^{2+}+\mathrm{Cu}^{0}
$$

This reaction is similar to opinions that have been expressed that some of the copper is formed by decomposition of cuprous to cupric sulfate ${ }^{2}$

$$
\mathrm{Cu}_{2} \mathrm{SO}_{4} \rightarrow \mathrm{CuSO}_{4}+\mathrm{Cu}
$$

Equation (2) leads to the secondary cementation reaction (around a copper powder grain ${ }^{3}$ ) that can be represented by the overall equation:

$$
4 \mathrm{Cu}+\mathrm{H}_{2} \mathrm{SeO}_{3}+2 \mathrm{H}_{2} \mathrm{SO}_{4} \rightarrow \mathrm{Cu}_{2} \mathrm{Se}+2 \mathrm{CuSO}_{4}+3 \mathrm{H}_{2} \mathrm{O}
$$

Simultaneously, the chemical reactions involved in the conversion of tetravalent and/or hexavalent telluric acid to copper telluride are: ${ }^{4}$

$$
\begin{gathered}
4 \mathrm{Cu}+\mathrm{H}_{2} \mathrm{TeO}_{3}+2 \mathrm{H}_{2} \mathrm{SO}_{4} \rightarrow \mathrm{Cu}_{2} \mathrm{Te}+2 \mathrm{CuSO}_{4}+3 \mathrm{H}_{2} \mathrm{O} \\
5 \mathrm{Cu}+\mathrm{H}_{6} \mathrm{TeO}_{6}+3 \mathrm{H}_{2} \mathrm{SO}_{4} \rightarrow \mathrm{Cu}_{2} \mathrm{Te}+3 \mathrm{CuSO}_{4}+6 \mathrm{H}_{2} \mathrm{O}
\end{gathered}
$$

The consumption of copper and sulfuric acid is in accord with the reactions given above. In this study, known amounts of copper chips and sulfuric acid were added during the tests as noted in the results and discussion. 


\section{Laboratory Bench Tests}

Laboratory bench tests were conducted on samples of autoclave leach filtrate which the concentration ranges shown in Table 1 to investigate the reduction rates of selenium and tellurium in the solution by using sulfur dioxide gas.

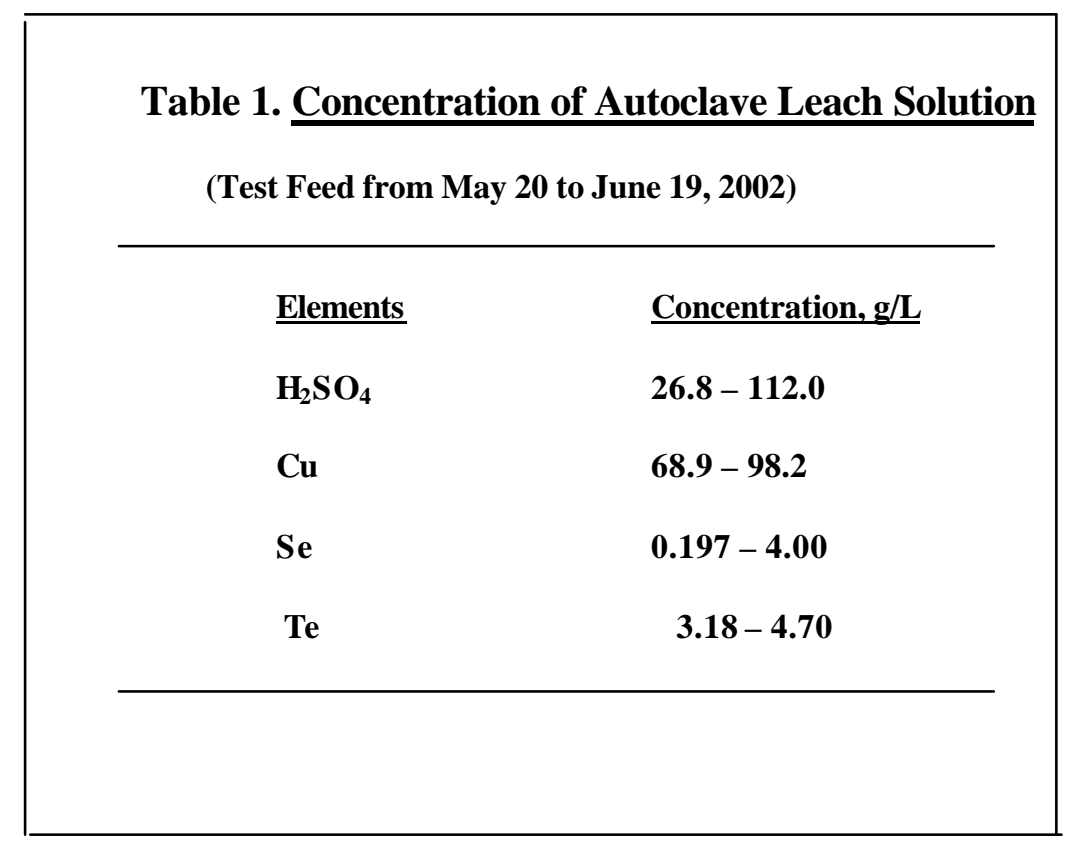

The sample was first analyzed for free acid and copper. If the free acid content was lower than required, according to the reaction equations 4 to 6 above, a calculated volume of sulfuric acid was added to the solution prior to the test.

The tests were performed in a 2-liter beaker sitting on a hot plate with an overhead mixer and a temperature control. Figure 4 shows a schematic diagram of the experimental apparatus. The sulfur dioxide was introduced to the solution in the reaction beaker through a gas sparger.

After reaction, the solution was filtered, the filtrate volume measured and the solids water washed. All samples were then submitted for chemical analyses. 


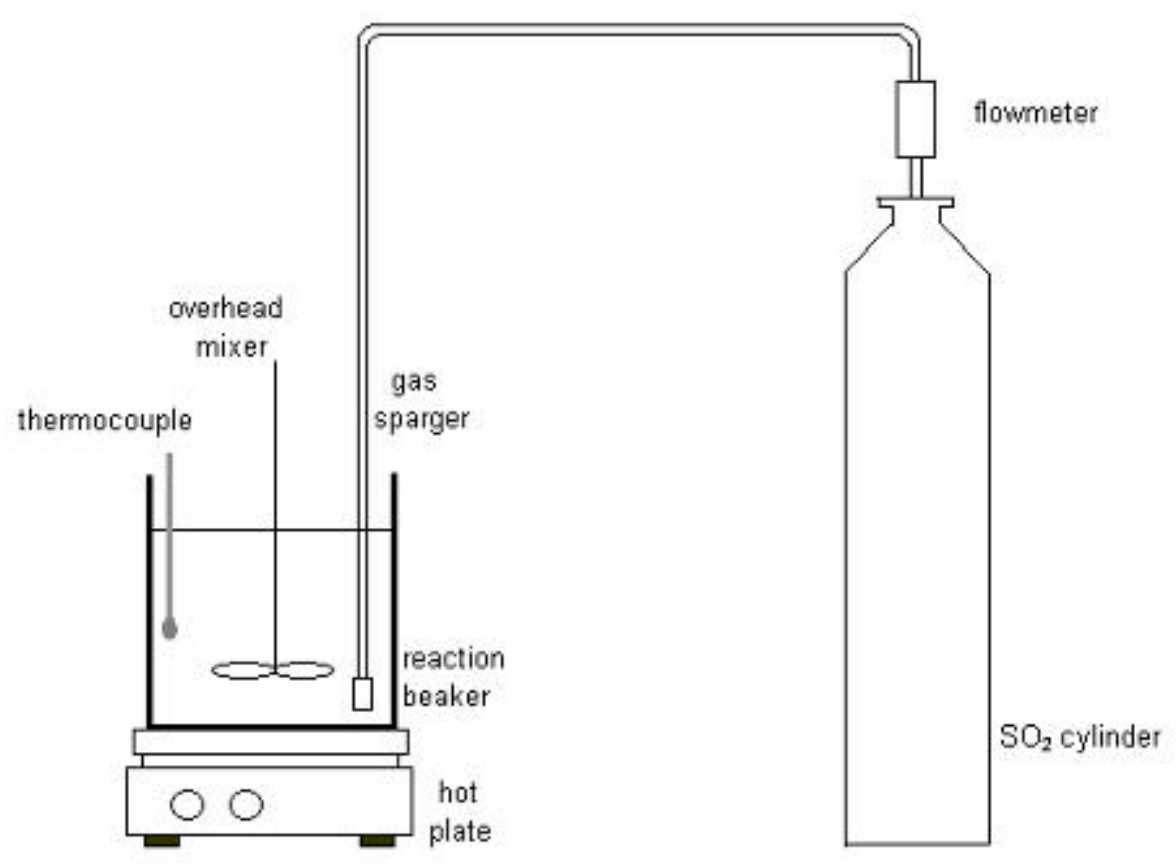

Figure 4. Schematic diagram of the experimental apparatus

\section{Test Results}

Reduction of selenium and tellurium was investigated on autoclave filtrate samples by blowing sulfur dioxide gas through them. In order to obtain adequate reduction kinetics, the acid concentration during the test was made up to greater than $80 \mathrm{~g} / \mathrm{L}$ sulfuric acid. For the same reason, the copper concentration was also maintained at above $50 \mathrm{~g} / \mathrm{L}$ by adding copper chips. During the study, the solution volume of 1.5 liters and the introduction rate of sulfur dioxide were kept constant. Very small quantities of copper chips, as a reducing enhancing agent, were added in the final stage of each test to guarantee the completion of reduction.

The kinetics of reduction of selenium and tellurium in the tests are presented in Figures 5 through 8. Characteristics of precipitates and analytical results of the precipitation of selenium and tellurium are summarized in Table 2. 


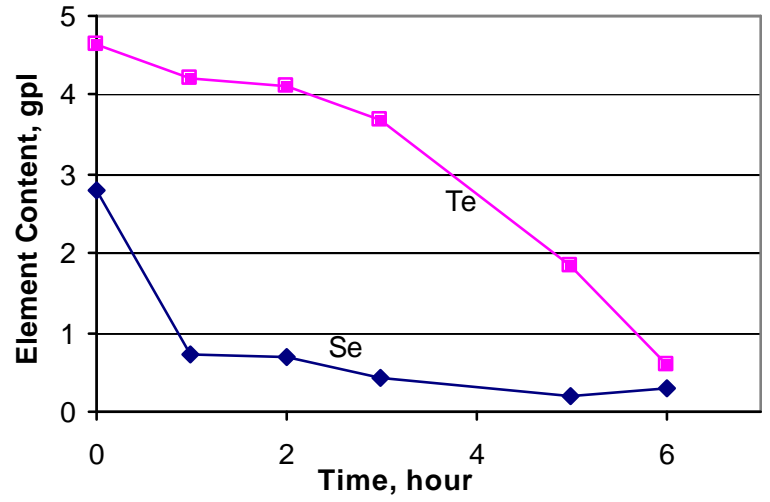

Figure 5. The Kinetics of Reduction of Se/Te from Test 1

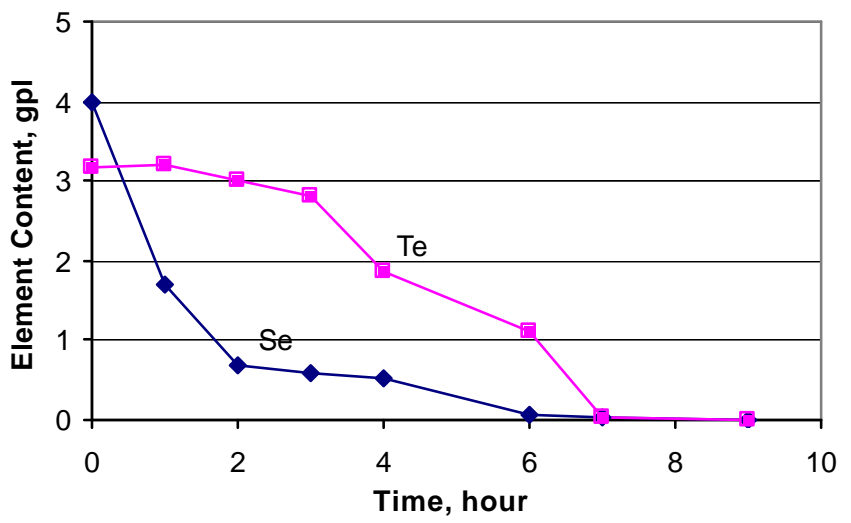

Figure 6. The Kenetics of Reduction of Se/Te from Test 2 

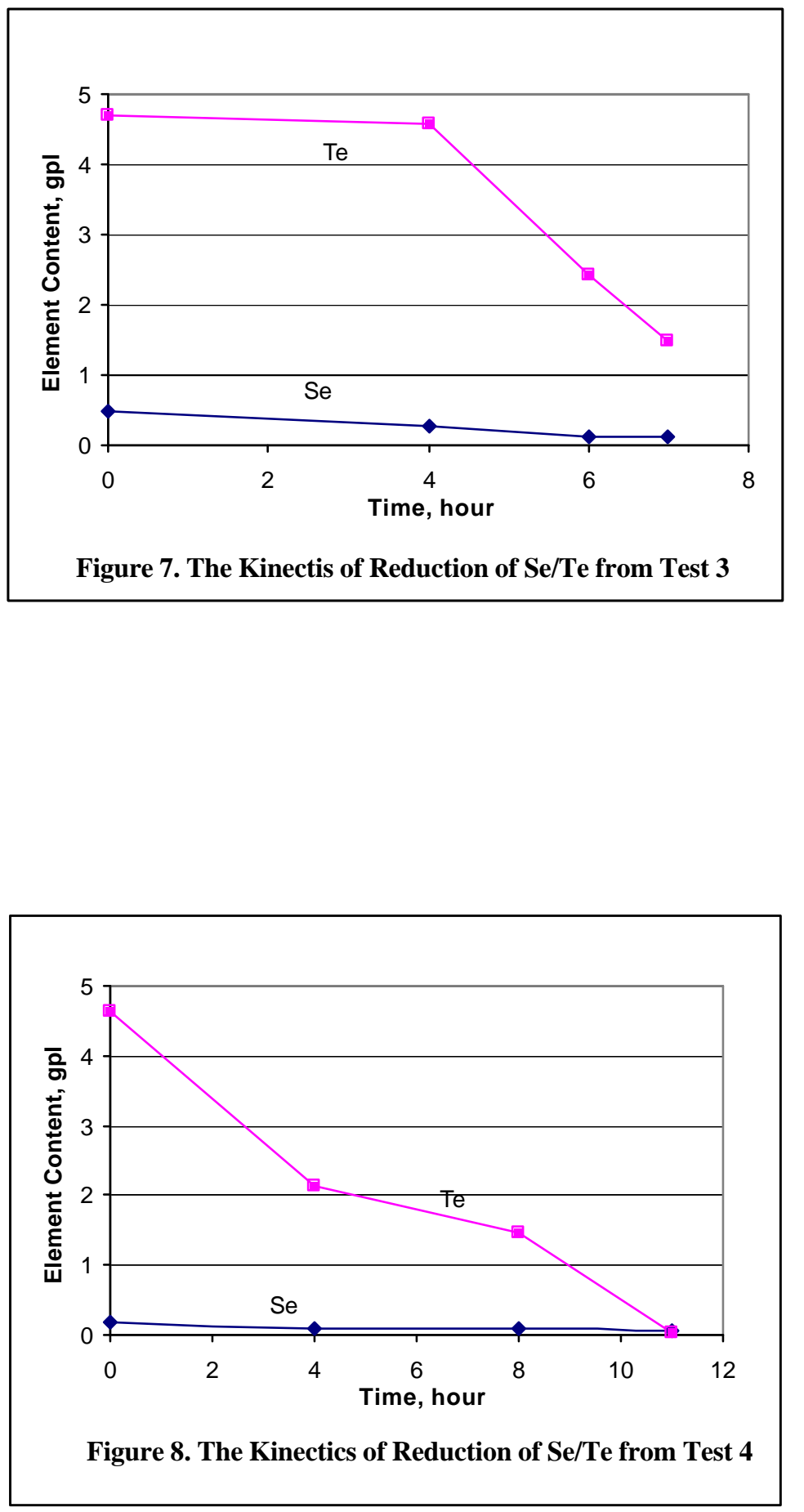


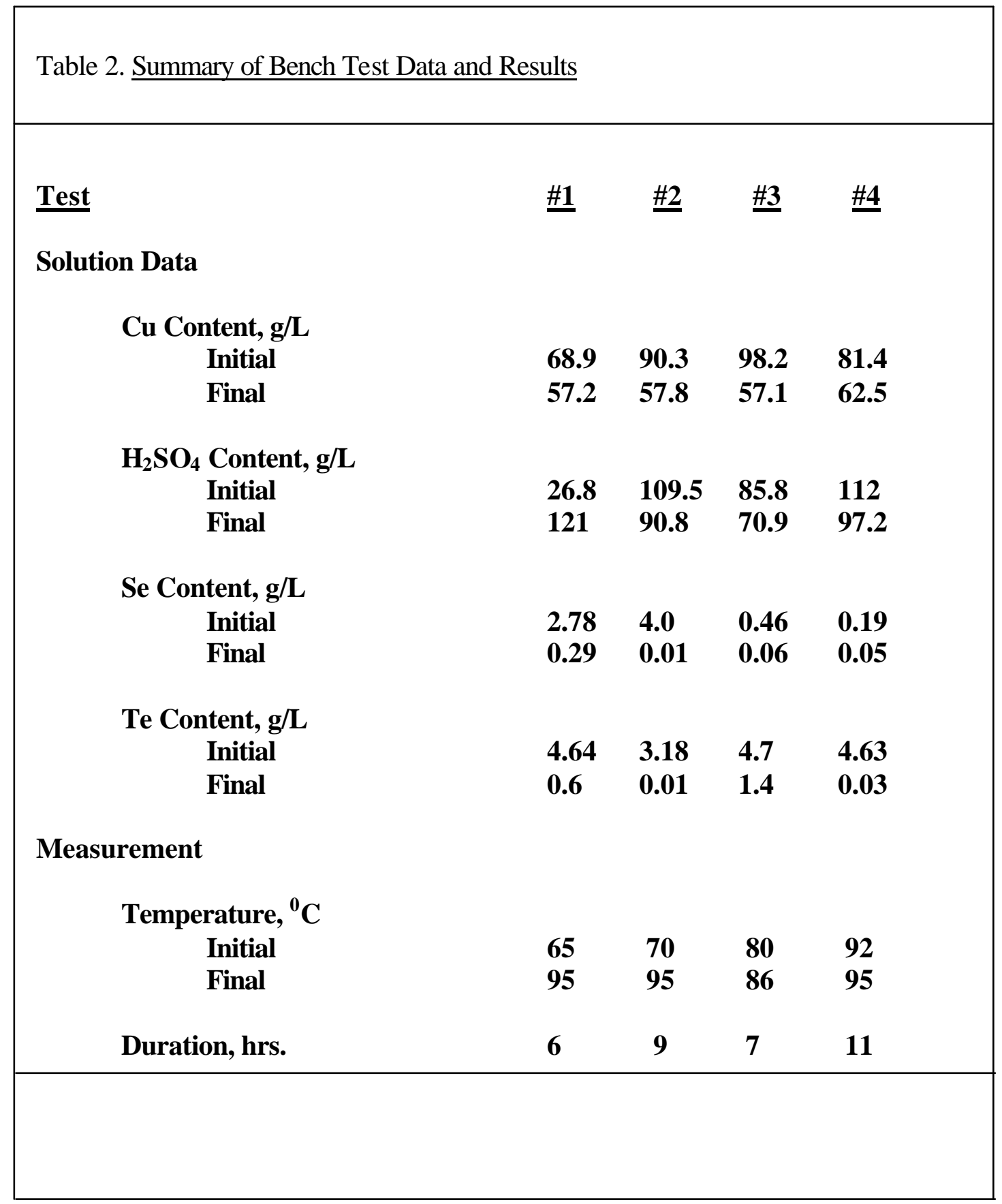




\section{Discussion}

\section{Reduction of selenium and tellurium:}

The reduction rate obtained showed that selenium, especially at an initial concentration of greater than $1 \mathrm{~g} / \mathrm{L}$, precipitated much faster than tellurium.

As shown in Figure 5 the reduction of selenium in sulfuric acid solution was very significant at the beginning. The concentration of selenium was reduced from 2.78 to $0.74 \mathrm{~g} / \mathrm{L}$ at $73^{\circ} \mathrm{C}$ and $107 \mathrm{~g} / \mathrm{L} \mathrm{H}_{2} \mathrm{SO}_{4}$ in 1 hour, while the tellurium concentration was only reduced from 4.64 to $4.20 \mathrm{~g} / \mathrm{L}$. After 5 hours when the copper concentration was reduced from 68.9 to 47.4 $\mathrm{g} / \mathrm{L}$, a total of 20 grams of copper chips was added directly to the solution in the beaker at a temperature of $92^{\circ} \mathrm{C}$. The copper chips, added as reducing agent, enhanced the reduction of tellurium and ended the test in one hour with final selenium and tellurium concentrations of 0.29 $\mathrm{g} / \mathrm{L}$ and $0.60 \mathrm{~g} / \mathrm{L}$, respectively.

As shown in Figure 6 the concentration of selenium in the solution was reduced from 4.0 to $0.7 \mathrm{~g} / \mathrm{L}$ at $75^{\circ} \mathrm{C}$ in 2 hours, while the tellurium concentration was only slightly reduced from 3.18 to $3.00 \mathrm{~g} / \mathrm{L}$. After 6 hours when the copper concentration was reduced from 90.3 to 25.9 $\mathrm{g} / \mathrm{L}$, a total of 30 grams of copper chips was added to the beaker. The test was completed at $95^{\circ} \mathrm{C}$, 9 hours, $81.4 \mathrm{~g} / \mathrm{L}$ copper and $112.0 \mathrm{~g} / \mathrm{L}$ sulfuric acid when the final concentration of $10 \mathrm{ppm}$ for both selenium and tellurium was obtained. The reduction time was significantly reduced to less than 10 hours compared to 24 or even 48 hours needed in reactors in the plant.

The results obtained showed a possibility of separation of selenium and tellurium by two stages of filtration in the treatment of autoclave leach solution. In Test 1 , for example, an initial filtration was performed after 3 hours of reduction and a second carried out at the end of the test. Two precipitates were thereby obtained. Results from SEM/EDAX analysis indicated that the copper selenide containing $47.78 \% \mathrm{Cu}, 47.56 \% \mathrm{Se}$ and $4.2 \%$ Te could be recycled to acid pressure leaching for recovery of selenium and the copper telluride; which contains $44.29 \% \mathrm{Cu}$, $46.56 \%$ Te and $0.95 \%$ Se, can be sold on the market.

\section{Effect of temperature on reduction:}

Temperature plays an important rule in the process chemistry. Although it did not show a significant effect on reduction of selenium by blowing sulfur dioxide gas, temperature dominated the reduction rate of tellurium during the test. As shown in Figure 7 the tellurium concentration was only slightly reduced from 4.70 to $4.57 \mathrm{~g} / \mathrm{L}$ in 4 hours when the maximum temperature was $80^{\circ} \mathrm{C}$. However, there was a period of fast precipitation of tellurium, as shown in Figure 8, when the temperature was greater than $92^{\circ} \mathrm{C}$. Tellurium concentration was reduced from 4.63 to 2.13 $\mathrm{g} / \mathrm{L}$ during the first 4 hours. The results obtained show that the reaction is even more rapid and greatly preferred at the boiling point during the process. 


\section{Effect of agitation on reduction:}

Fine copper powder, formed from the disproportionation reaction, was an efficient precipitant but its use was not sufficient because of its concentration. This resulted in the need to add copper chips to enhance the reduction rate of tellurium. A coating of copper telluride, however, built up on the surfaces of the copper powder/chips and rendered them inactive; indicating that copper could be reused only if the reaction product was continuously removed from the surfaces. This requirement was met by employing an overhead mixer to agitate the heated solution and to flush away copper selenide and copper telluride from the copper surfaces in the reactor.

\section{An effective and efficient new process:}

As shown in Table 3, focusing on advantages and disadvantages of current existing and new processes, it is apparent that an efficient and economic process for treating slimes autoclave leach solution could be developed in a dedicated tank (Figure 4) with an emphasis on a chemical reducing agent (sulfur dioxide, $\mathrm{SO}_{2}$ ) and enhanced performance (copper, $\mathrm{Cu}^{0}$ ) for the recovery of tellurium. The new process that has direct heating in the reactor could cut down the operational time significantly and reduce the copper consumption tremendously in formations of copper telluride.

Table 3. Summary of Advantages and Disadvantages of the Current and New Processes

\begin{tabular}{|l|l|}
\hline \multicolumn{1}{|c|}{ Advantages } & \multicolumn{1}{c|}{ Disadvantages } \\
\hline Current Process & \\
\hline $\begin{array}{l}\text { 1. Existing facility } \\
\text { 2. Environmental emission free }\end{array}$ & $\begin{array}{l}\text { 1. Low efficiency and high operational } \\
\text { cost }\end{array}$ \\
& $\begin{array}{l}\text { 2. Low production rate and affects } \\
\text { autoclaving operation }\end{array}$ \\
& $\begin{array}{l}\text { 3igh copper consumption and low } \\
\text { metal value recovery }\end{array}$ \\
\hline New Process & $\begin{array}{l}\text { 1. Possible capital needed } \\
\text { 1. high efficiency and low operational } \\
\text { cost }\end{array}$ \\
$\begin{array}{l}\text { 2. high production rate } \\
\text { 3. } \begin{array}{l}\text { very low copper consumption and } \\
\text { high metal value recovery }\end{array}\end{array}$ \\
\hline
\end{tabular}




\section{Conclusions}

Conclusions from the bench tests are as follows:

- Using sulfur dioxide as a reducing agent is an efficient method to remove selenium and tellurium from autoclave leach solution.

- Selenium and tellurium can be separately recovered from the solution as two by-products: copper selenide and copper telluride.

- The new process that is developed based on this investigation results could cut down the operational time significantly and reduce the copper consumption tremendously in formations of copper selenide and copper telluride.

\section{Acknowledgements}

The authors would like to express their appreciation to plant personnel who worked on this project.

\section{References}

1. W.C. Cooper, P.H. Jennings, etc., Tellurium, Van Nostrand Reinhold Company, 1971, p. 34

2. J.H. Schloen and E.M. Elkin, Treatment of Electrolytic Copper Refinery Slimes, Journal of Metals, May 1950, pp $764-777$.

3. J. Scott, Electrometallurgy of Copper Refinery Anode Slimes, Matallrugical Transaction B, Vol 21B, August 1990, pp 629 - 635

4. J.E. Hoffmann, Process and Engineering Considerations in the Pressure Leaching of Copper Refinery Slimes, EPD Congress 2000, pp397 - 411 